\title{
Diapycnal Mixing in the Antarctic Circumpolar Current
}

\author{
J. R. LEDWELl AND L. C. ST. LAURENT \\ Woods Hole Oceanographic Institution, Woods Hole, Massachusetts \\ J. B. GIRTON \\ Applied Physics Laboratory, University of Washington, Seattle, Washington \\ J. M. TOOLE \\ Woods Hole Oceanographic Institution, Woods Hole, Massachusetts
}

(Manuscript received 17 August 2010, in final form 5 October 2010)

\begin{abstract}
The vertical dispersion of a tracer released on a density surface near 1500-m depth in the Antarctic Circumpolar Current west of Drake Passage indicates that the diapycnal diffusivity, averaged over 1 yr and over tens of thousands of square kilometers, is $(1.3 \pm 0.2) \times 10^{-5} \mathrm{~m}^{2} \mathrm{~s}^{-1}$. Diapycnal diffusivity estimated from turbulent kinetic energy dissipation measurements about the area occupied by the tracer in austral summer 2010 was somewhat less, but still within a factor of 2 , at $(0.75 \pm 0.07) \times 10^{-5} \mathrm{~m}^{2} \mathrm{~s}^{-1}$. Turbulent diapycnal mixing of this intensity is characteristic of the midlatitude ocean interior, where the energy for mixing is believed to derive from internal wave breaking. Indeed, despite the frequent and intense atmospheric forcing experienced by the Southern Ocean, the amplitude of finescale velocity shear sampled about the tracer was similar to background amplitudes in the midlatitude ocean, with levels elevated to only $20 \%-50 \%$ above the Garrett-Munk reference spectrum. These results add to a long line of evidence that diapycnal mixing in the interior middepth ocean is weak and is likely too small to dictate the middepth meridional overturning circulation of the ocean.
\end{abstract}

\section{Introduction}

In the middle of the twentieth century, the prevailing view of the ocean circulation below the main pycnocline was that deep and bottom waters were subject to a widescale upwelling of order $10^{-7} \mathrm{~m} \mathrm{~s}^{-1}$ (Stommel and Arons 1960; Wyrtki 1961; and others). The implication of a diapycnal diffusivity of $10^{-4} \mathrm{~m}^{2} \mathrm{~s}^{-1}$ then followed from the idea that observed vertical profiles of temperature, salinity, radioisotopes, and oxygen between 1000- and 4000-m depth were maintained by a balance among diapycnal advection, diapycnal diffusion, and, for radioisotopes and oxygen, decay or biological uptake (Munk 1966; Munk and Wunsch 1998).

More recent measurements of turbulent dissipation (e.g., Gregg et al. 1973; Osborn 1980; Gregg 1989) and

Corresponding author address: James R. Ledwell, Mail Stop 12, Woods Hole Oceanographic Institution, Woods Hole, MA 02543. E-mail: jledwell@whoi.edu passive tracer spreading rates (Ledwell et al. 1998) have suggested that the diapycnal diffusivity in the middepth ocean interior is on the order of $10^{-5} \mathrm{~m}^{2} \mathrm{~s}^{-1}$, that is, a factor of 10 smaller than predicted by large-scale balance models. Although turbulence has been found to be greatly enhanced near bathymetric features (e.g., Polzin et al. 1997; St. Laurent and Thurnherr 2007), there does not seem to be enough topography at middepth (1000-4000 m-the range of depth occupied by steep continental slopes) for topographically enhanced mixing to make up for the near absence of interior mixing and yield a globally averaged value of order $10^{-4} \mathrm{~m}^{2} \mathrm{~s}^{-1}$ (Kunze and Toole 1997). Turbulent dissipation measurements remain sparse and mostly limited to midand low latitudes (Gregg et al. 1973; Toole et al. 1994; Gregg et al. 2003; Klymak et al. 2006). Measurements of vertical shear and strain at scales of tens of meters, from which mixing estimates can be inferred, are more widespread, but formulations relating these internal wave characteristics to dissipation rates and diapycnal 


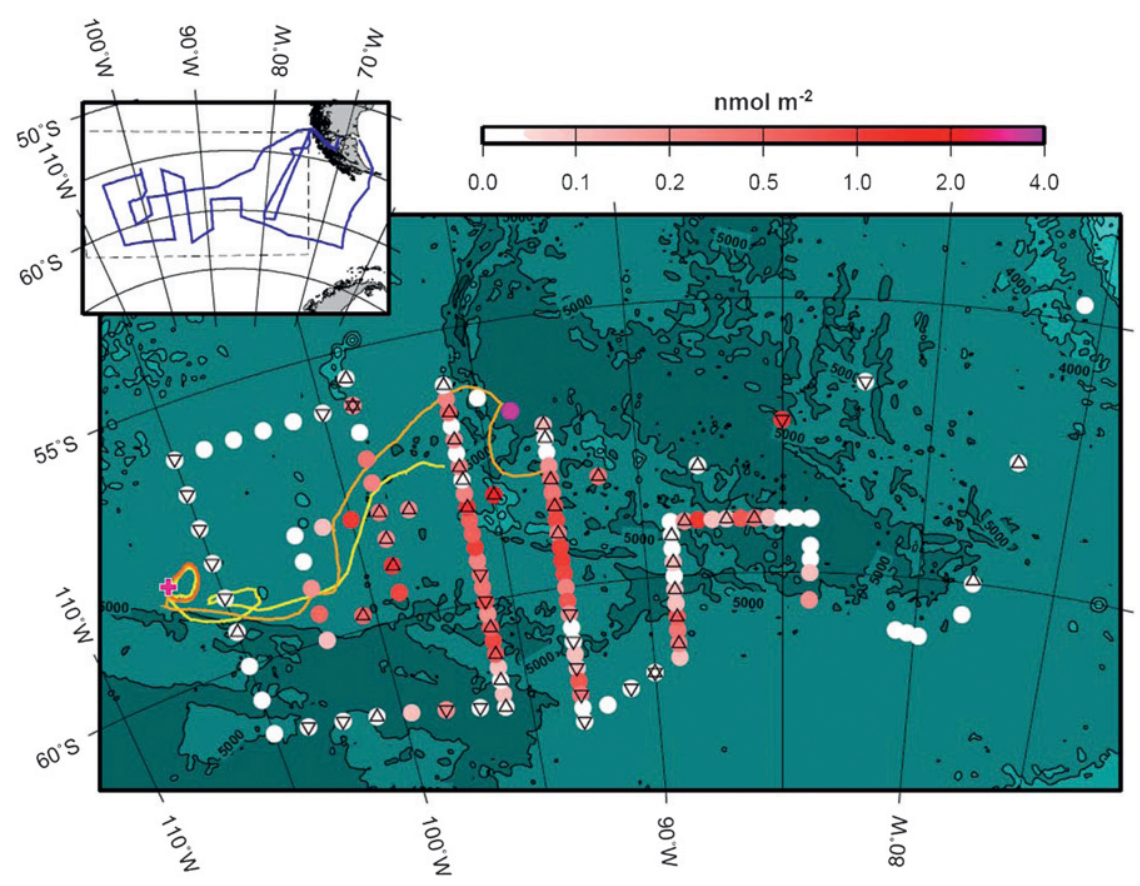

FIG. 1. Bathymetric chart showing the 2009 injection site (fuchsia plus sign near $107^{\circ} \mathrm{W}$ ), 2010 CTD/tracer stations (filled circles, with color indicating tracer column integral; nmol m${ }^{-2}$ ), HRP2 stations (upright triangles), DMP stations (inverted triangles), and 2009 EM-APEX float tracks (three yellow-brown tracks starting at the tracer release site and representing drifts of 63,274 , and 283 days). The inset shows the full 2010 cruise track; the dashed box marks the boundaries of the expanded-scale plot.

diffusivity are subject to a number of added approximations (Gregg 1989; Kunze et al. 2006). The Southern Ocean is a large and energetic part of the ocean that has until very recently remained unsampled by the more direct methods.

Here we report a direct measurement of diapycnal diffusivity of a passive tracer in deep water, along with finescale shear and turbulent dissipation measurements in the strongly wind-driven Antarctic Circumpolar Current (ACC). Our study is part of the Diapycnal and Isopycnal Mixing Experiment in the Southern Ocean (DIMES).

\section{Observations and results}

\section{a. Tracer diffusion}

The tracer, $76 \mathrm{~kg}$ of trifluoromethyl sulphur pentafluoride $\left(\mathrm{CF}_{3} \mathrm{SF}_{5}\right)$, was released from Research Vessel (R/V) Roger Revelle on the $27.906 \mathrm{~kg} \mathrm{~m}^{-3}$ neutral density surface in two 20-km-long streaks forming an " $X$ " pattern near $58^{\circ} \mathrm{S}, 107^{\circ} \mathrm{W}$ in early February of 2009 (Fig. 1). This location was between the Polar Front and the Subantarctic Front, where the depth of the target isopycnal surface was approximately $1500 \mathrm{~m}$. The mean salinity, temperature, and pressure during injection were $34.6484,2.295^{\circ} \mathrm{C}$, and $1573 \mathrm{dbar}$, respectively. The target surface lay near the boundary between Upper and Lower Circumpolar Deep Water, about $100 \mathrm{~m}$ below the oxygen minimum. Hydrographic characteristics near the injection site, including front locations, were very similar to those seen in World Ocean Circulation Experiment Section P18 (McTaggart et al. 1996; Talley 2007), which passed near this site. The initial diapycnal distribution of the tracer was measured with conventional CTD rosette casts and with a towed array of integrating samplers (Ledwell et al. 1998). The mean of the 11 rosette profiles that found tracer (Fig. 2) indicates that the center of mass of the tracer was about $3 \mathrm{~m}$ below the target surface, possibly because of sinking before the tracer dissolved; the rms spread of the tracer, transformed to depth through the mean density gradient, was $5.5 \mathrm{~m}$. The mean profile from three tows (not shown) of the integrating samplers was similar.

The tracer patch was surveyed a year later, in JanuaryFebruary of 2010, from R/V Thomas G. Thompson (Fig. 1). Eighty-two vertical profiles with measurable tracer concentration were obtained with a conventional CTD rosette. When averaged as a function of neutral density and then transformed to depth coordinates through the mean depth-density relation for the survey region, they yield a near-Gaussian mean profile with a standard 


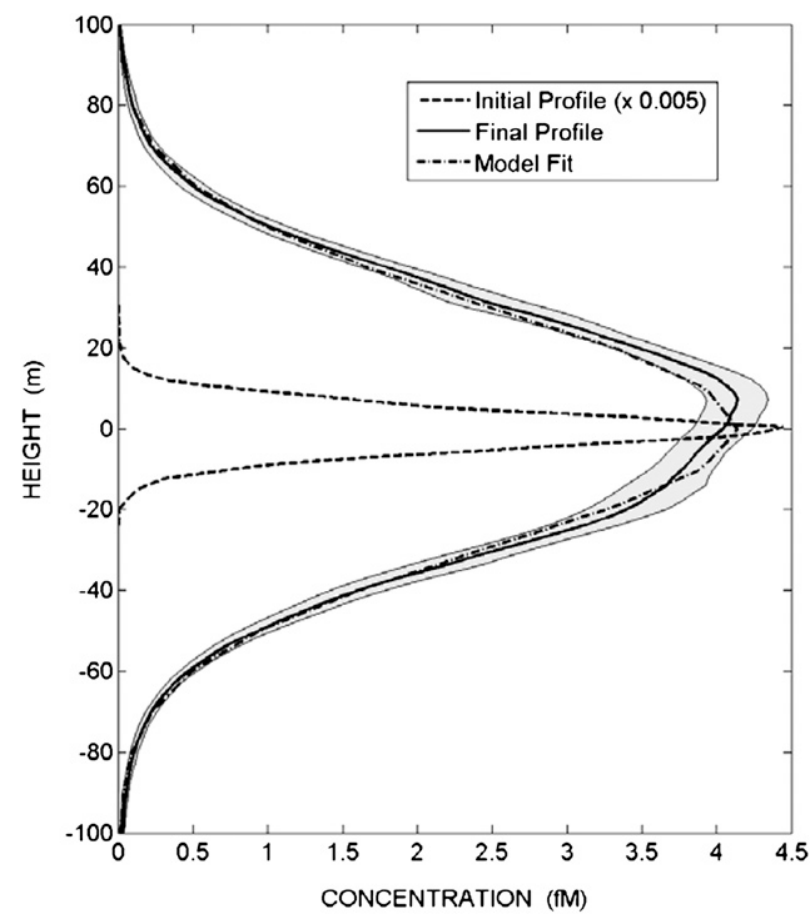

FIG. 2. Mean tracer profiles. The ordinate is height relative to the mode of the initial profile. Dashed curve: initial mean concentration measured shortly after release, multiplied by 0.005 . Solid curve: final mean profile measured $1 \mathrm{yr}$ later. The gray uncertainty envelope is based on variations of the shape of individual profiles, as in Ledwell and Bratkovich (1995). Dash-dotted curve: final profile for an integration of the one-dimensional diffusion equation, starting with the initial profile, for a diapycnal diffusivity of $1.28 \times 10^{-5} \mathrm{~m}^{2} \mathrm{~s}^{-1}$.

deviation of $29.5 \mathrm{~m}$ (Fig. 2). Although the depth of the target neutral density surface shoaled from 1800 to $1000 \mathrm{~m}$ from north to south across the tracer patch, the vertical density stratification in the layer occupied by the tracer was fairly constant at $2.65 \times 10^{-4} \mathrm{~kg} \mathrm{~m}^{-4}$, with root-mean-square variations of $0.18 \times 10^{-4} \mathrm{~kg} \mathrm{~m}^{-4}$, uncorrelated with the depth. The center of the 1-yraverage profile was within a few meters of the initial isopycnal surface, with uncertainty arising mainly from salinity calibrations. Evolution of the initial profile to the 1-yr profile was modeled with the one-dimensional diffusion equation and a constant diffusivity (Ledwell et al. 1998). The resulting diffusivity estimate, which reflects diapycnal mixing over the entire region occupied by the tracer indicated in Fig. 1 and over a full year, is $(1.3 \pm 0.2) \times 10^{-5} \mathrm{~m}^{2} \mathrm{~s}^{-1}$. The uncertainty is an estimate of the $95 \%$ confidence interval based on variations of the cost function with diffusivity in the model, uncertainty in the appropriate density profile to apply, and also on the different result obtained $\left(1.33 \times 10^{-5}\right.$ vs $1.28 \times$ $10^{-5} \mathrm{~m}^{2} \mathrm{~s}^{-1}$ ) by simply calculating diffusivity from the difference between the second moment of Gaussians fit to the initial and final profiles.

\section{b. Microstructure profiling}

Measurements of fine- and microscale parameters were acquired at a subset of tracer survey stations during the 2010 cruise using two profiling instrument systems: High Resolution Profiler 2 (HRP2), built at the Woods Hole Oceanographic Institution, and a Rockland Scientific International, Inc., Deep Microstructure Profiler (DMP). HRP2 is similar to the original HRP (Schmitt et al. 1988). Further details on the DMP instrument system are described online (at http://www.rocklandscientific.com). Both instruments measure centimeter-scale shear $(\partial u / \partial z)$, from which the dissipation rate of turbulent kinetic energy $\varepsilon=(15 \nu / 2) \overline{(\partial u / \partial z)^{2}}$ may be estimated, where $\nu$ is the molecular viscosity and isotropy is assumed. For the ensemble of 49 dissipation profiles acquired in the area of the tracer patch, the average dissipation rate based on samples within $\pm 250 \mathrm{~m}$ of the tracer release isopycnal was $1.09 \times 10^{-10} \mathrm{~W} \mathrm{~kg}^{-1}$. Ninety-five-percent confidence bounds, derived using a bootstrap procedure involving repeated subsampling of the available $1-\mathrm{m}$ dissipation estimates, range between $9.93 \times 10^{-11}$ and $1.19 \times 10^{-10} \mathrm{~W} \mathrm{~kg}^{-1}$. The corresponding diapycnal diffusivity estimate, derived assuming a turbulent kinetic energy budget in statistical steady state (Osborn 1980), is $k_{\rho}=\Gamma\langle\varepsilon\rangle /\left\langle N^{2}\right\rangle=(0.75 \pm 0.07) \times 10^{-5} \mathrm{~m}^{2} \mathrm{~s}^{-1}$, where $\Gamma$ is the mixing efficiency parameter, taken to be 0.2 [see, e.g., Oakey (1982) and St. Laurent and Schmitt (1999) for justification of this choice], and $\left\langle N^{2}\right\rangle$ is the average buoyancy gradient over the tracer patch.

The area-averaged dissipation profile for the tracer survey region (averages done on pressure surfaces) decreased roughly monotonically with depth below the surface layers that are directly forced by the atmosphere (Fig. 3a). The corresponding diffusivity profile exhibits a local minimum between 500- and 1000-m depth where average values fall to around $5 \times 10^{-6} \mathrm{~m}^{2} \mathrm{~s}^{-1}$, just 40 times the molecular diffusivity for temperature (Fig. 3b). Average diffusivity increased to around $1.2 \times$ $10^{-5} \mathrm{~m}^{2} \mathrm{~s}^{-1}$ at and below $2000 \mathrm{~m}$. The regional water depth is approximately $4700 \mathrm{~m}$, averaged along the survey track of Fig. 1, and the bottom is smooth when compared with other sectors of the ACC. The deepest microstructure profiles of the survey ranged in height above local bottom between 213 and $2180 \mathrm{~m}$ with an average of $1084 \mathrm{~m}$. No evidence of enhanced deep turbulent dissipation was seen in those profiles that extended to within $500 \mathrm{~m}$ of the bottom.

\section{c. Finescale shear measurements}

Instability and breaking of internal waves is believed to be the principal source of energy for turbulence in the ocean interior (Munk 1981). Finescale velocity profile 


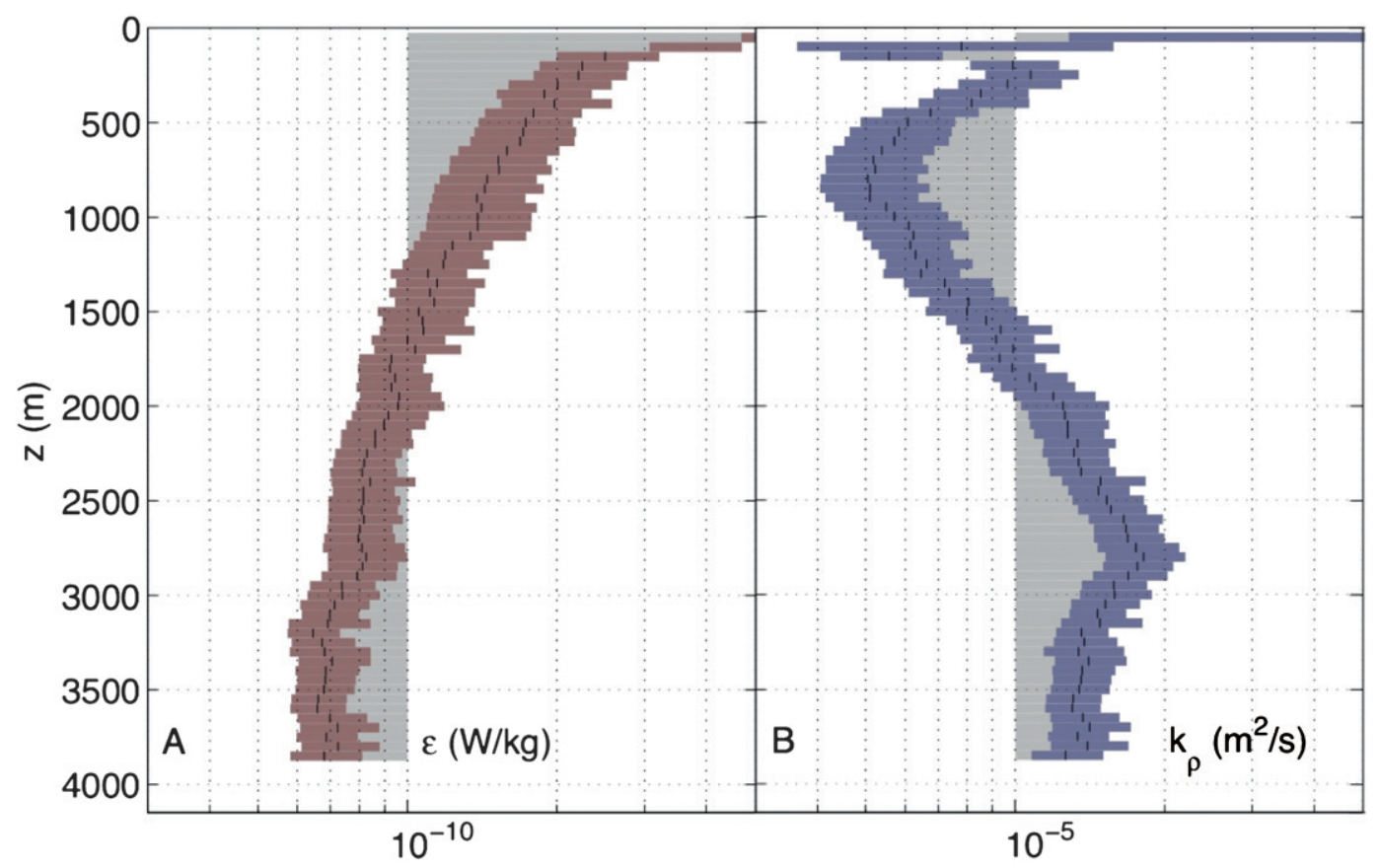

FIG. 3. Mean profiles of (a) turbulent kinetic energy dissipation $\varepsilon$ and (b) diapycnal diffusivity $k_{\rho}$, estimated from velocity microstructure data. Mean estimates of $\varepsilon$ and $k_{\rho}$ are off scale in the upper $100 \mathrm{~m}$, reaching values of $1 \times$ $10^{-7} \mathrm{~W} \mathrm{~kg}^{-1}$ and $1 \times 10^{-3} \mathrm{~m}^{2} \mathrm{~s}^{-1}$, respectively.

data were acquired by HRP2 during the 2010 cruise using procedures similar to Schmitt et al. (1988), and on longer a time scale by freely drifting Electromagnetic Autonomous Profiling Explorer (EM-APEX) floats (Sanford et al. 2005, 2007). Three EM-APEX floats were deployed with the tracer injection and sampled from 3 February to 27 November 2009 (Fig. 1); four more were launched within the tracer patch during the 2010 R/V Thompson cruise. Sampling was primarily in bursts of four profiles (two up and two down, reaching 1500 and $2000 \mathrm{~m}$ ) every 5 days, with the up-profile pair separated by one-half times the local inertial frequency (approximately $7 \mathrm{~h}$ ) to allow for diagnosis of near-inertial motions. Horizontal velocity components were processed using a 50-s (approximately $6 \mathrm{~m}$ ) window and the local geomagnetic parameters from the International Geomagnetic Reference Field (Macmillan and Maus 2005).

Vertical wavenumber power spectral energy density estimates $\left(P_{u u}\right.$ and $\left.P_{v v}\right)$ for HRP2 and EM-APEX profiles were computed from 500-m segments of east $(u)$ and north $(v)$ velocity components centered on the tracer isopycnal depth and, in the latter case, corrected for the processing window by dividing by $\operatorname{sinc}^{2}\left(k_{z} \lambda_{0}\right)$, where $k_{z}$ is the wavenumber (cpm) and $\lambda_{0}=6 \mathrm{~m}$. Shear periodograms were then computed as $P_{s}=\left(P_{u u}+P_{v v}\right)\left(2 \pi k_{z}\right)^{2}$, and the respective ensembles of periodograms were averaged together to generate the shear spectra in Fig. 4a. Shear variance time series (Fig. 4b) were computed by integrating the individual EM-APEX shear periodograms below $0.1 \mathrm{cpm}$.

Finescale shear variability about the tracer injection isopycnal sampled during the R/V Thompson cruise by the HRP2 (Fig. 4a) was similar in vertical wavenumber content and somewhat higher in level than the so-called Garrett-Munk (GM) spectrum that characterizes the midlatitude background internal wave field (Garrett and Munk 1975; Cairns and Williams 1976; Gregg and Kunze 1991). Models relating finescale shear to turbulent dissipation rate (e.g., Gregg 1989; Polzin et al. 1995) predict a "background" diffusivity of $\kappa_{\mathrm{GM}}=0.5 \times 10^{-5} \mathrm{~m}^{2} \mathrm{~s}^{-1}$ and a scaling of diffusivity with the square of the shear spectral level, that is, model diffusivity varying with the fourth power of the shear. Thus, for the HRP2 shear spectral level of $1.2 \times \mathrm{GM}$ (below $2 \times 10^{-2} \mathrm{cpm}$, where the level is uncontaminated by instrument motion), these models predict a diapycnal diffusivity of $1.5 \times \kappa_{\mathrm{GM}}=$ $0.75 \times 10^{-5} \mathrm{~m}^{2} \mathrm{~s}^{-1}$, identical to the estimate based on the turbulent dissipation estimates.

The average shear spectrum from the EM-APEX floats deployed during the 2010 cruise is at a level nearly identical to that sampled by the HRP2 (Fig. 4a). The 2009 group, of longer duration and thus returning data that were more representative of the conditions seen by the evolving tracer patch, measured an average shear spectral level of $1.5 \times \mathrm{GM}$. This corresponds to a model diffusivity of $2.3 \times \kappa_{\mathrm{GM}}=1.15 \times 10^{-5} \mathrm{~m}^{2} \mathrm{~s}^{-1}$, very close 


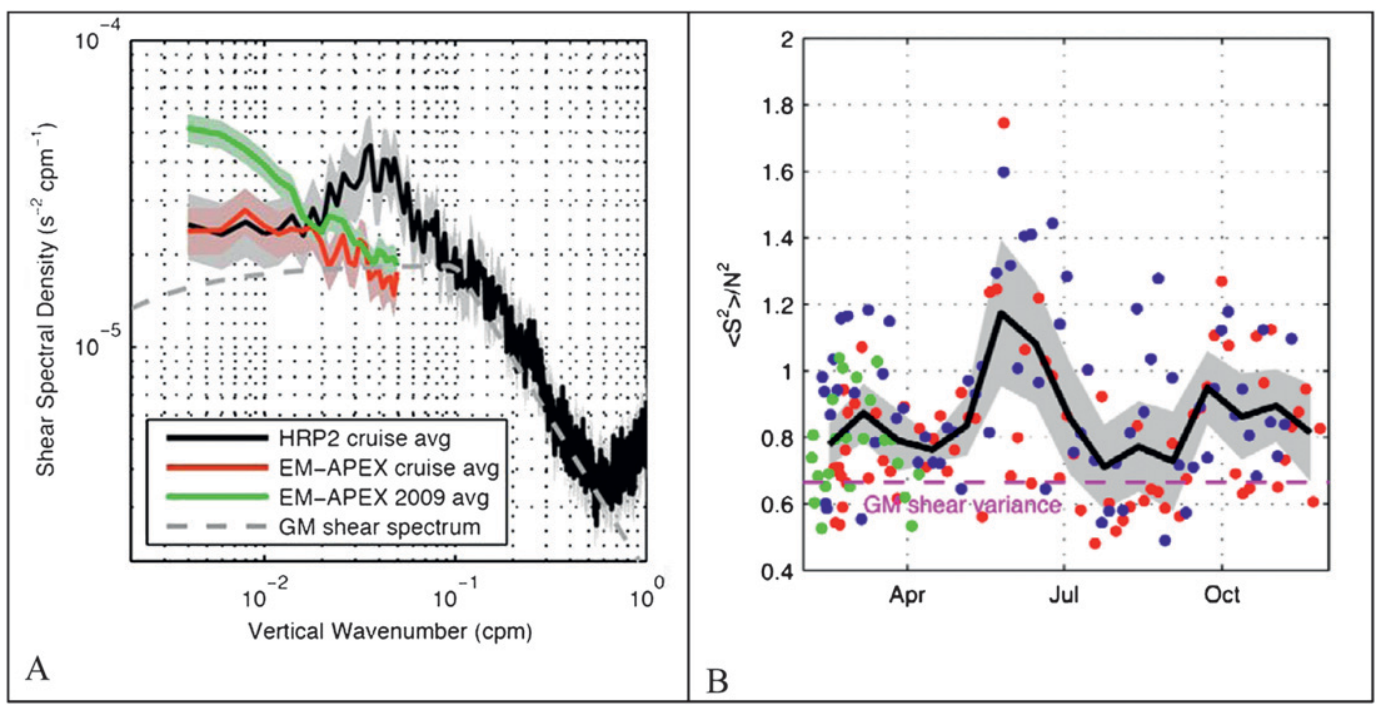

FIG. 4. (a) Vertical wavenumber spectrum of total shear from HRP2 (31 profiles) and EM-APEX floats for a 500-m window centered on the tracer injection surface (cruise average: 64 profiles; 2009 average: 172 profiles). Also shown (gray dashes) is the GM reference shear spectrum for the observed buoyancy frequency. The enhanced energy density in the HRP2 spectrum at wavenumbers between $2 \times 10^{-2}$ and $6 \times 10^{-2} \mathrm{cpm}$ is believed to be an artifact of the instrument's motion; noise dominates the HRP2 spectrum at wavenumbers above $6 \times 10^{-1} \mathrm{cpm}$. Gray uncertainty bands were estimated using the method of Gregg and Kunze (1991). (b) Time series of finescale shear variance from the three EM-APEX floats deployed with the tracer in 2009, normalized by buoyancy frequency squared, along with the corresponding GM level. Individual samples (dots, color coded by instrument) are computed from 500-m profile segments centered on the tracer injection surface. The thick line indicates 20 -day averages with $95 \%$ confidence interval shading.

to the value estimated from the observed tracer diapycnal dispersion after 1 yr. Periods of enhanced shear in March, May-June, and September-October seen in the time series of shear variance (Fig. 4b) are associated with downward-propagating near-inertial packets with vertical wavelength of around $200 \mathrm{~m}\left(5 \times 10^{-3} \mathrm{cpm}\right)$ diagnosed from profile pairs. These packets are presumably forced by high-frequency wind variability at the surface.

Thus, the difference of nearly a factor of 2 between the diffusivity estimated from the tracer dispersion and that estimated from kinetic energy dissipation is consistent with the elevated shear variance in the winter relative to that during the summer when dissipation rates were measured. We note that double diffusion is unlikely to have enhanced the tracer diffusivity, as appeared to be the case in the North Atlantic Tracer Release Experiment (St. Laurent and Schmitt 1999), since salinity decreases with height almost everywhere in the region occupied by the tracer, the mean density ratio being -0.36 .

\section{Discussion}

The depth of the neutral density surface of the tracer release is around $2000 \mathrm{~m}$ equatorward of the subpolar fronts, that is, near the center of the depth range for which Munk (1966) famously inferred a basinwide diapycnal diffusivity of $1.3 \times 10^{-4} \mathrm{~m}^{2} \mathrm{~s}^{-1}$ for the $\mathrm{Pa}$ cific Ocean. Others have suggested that a mixing rate of $O\left(1 \times 10^{-5}\right) \mathrm{m}^{2} \mathrm{~s}^{-1}$ is sufficient for the deep water of the Southern Ocean (Toggweiler and Samuels 1998; Webb and Suginohara 2001). We concur with those latter authors, noting that the amplitude of the middepth internal wave field in this region away from prominent topography is only marginally more intense than the background amplitude at midlatitude. Correspondingly, the turbulent mixing driven by this wave field supports an average diapycnal diffusivity only of order $10^{-5} \mathrm{~m}^{2} \mathrm{~s}^{-1}$.

Diapycnal mixing may be enhanced in more energetic regions of the ACC, such as over the rough topography of Drake Passage and the Scotia Sea (Heywood et al. 2002; Naveira Garabato et al. 2004), Kerguelen Plateau (Waterman et al. 2010), and Macquarie Ridge south of New Zealand. Enhanced mixing found near boundaries and above rough bathymetry seems sufficient to provide the necessary buoyancy flux for the return flow of bottom water (Polzin et al. 1997; Ledwell et al. 2000), but we are skeptical that there is sufficient enhancement at middepth to support an oceanwide diffusivity of $10^{-4} \mathrm{~m}^{2} \mathrm{~s}^{-1}$. DIMES will continue with a study of mixing in Drake Passage and the Scotia Sea, as the tracer passes through those much rougher regions, to examine this question further. 
Acknowledgments. This paper is dedicated to the family and shipmates of Captain Philip Alan Smith, who died on 18 January 2010 while at sea on R/V Thompson. We thank the crews and technicians on $\mathrm{R} / \mathrm{V}$ Roger Revelle and R/V Thomas G. Thompson and their home institutions for their excellent support. Invaluable assistance with the work was provided by Ryan Abernathy, Larry Anderson, Angel Ruiz Angulo, Magdalena Carranza, David Ciochetto, Gillian Damerell, Ken Decoteau, Catherine Grendi, Brian Guest, Jay Hooper, Leah Houghton, Byron Kilbourne, Valery Kosneyrev, Andrew Kowalczyk, Rick Krishfield, Steven Lambert, Peter Lazarevich, Craig Rye, Cynthia Sellers, Stewart Sutherland, David Wellwood, Nicolas Wienders, Cimarron Wortham, and Uriel Zajaczkovski. We thank our fellow DIMES investigators, especially Karen Heywood, Alberto Naveira Garabato, and Andrew Watson, all of the U.K., for substantial support. We likewise thank Alberto Piola of Argentina and Carlos Moffat of Chile. This material is based upon work supported by the National Science Foundation Grants OCE-0622825, OCE-0622670, OCE-0622630, and OCE-0623177.

\section{REFERENCES}

Cairns, J., and G. Williams, 1976: Internal wave observations from a midwater float, 2. J. Geophys. Res., 81, 1943-1950.

Garrett, C. J. R., and W. H. Munk, 1975: Space-time scales of internal waves: A progress report. J. Geophys. Res., 80, 291-297.

Gregg, M. C., 1989: Scaling turbulent dissipation in the thermocline. J. Geophys. Res., 94, 9686-9698.

-, and E. Kunze, 1991: Internal wave shear and strain in Santa Monica Basin. J. Geophys. Res., 96, 16 709-16 719.

— C. S. Cox, and P. W. Hacker, 1973: Vertical microstructure measurements in the central North Pacific. J. Phys. Oceanogr., 3, 458-469.

_ T. B. Sanford, and D. P. Winkel, 2003: Reduced mixing from the breaking of internal waves in equatorial waters. Nature, 422, 513-515.

Heywood, K. J., A. C. Naveira Garabato, and D. P. Stevens, 2002: High mixing rates in the abyssal Southern Ocean. Nature, 415, 1011-1014.

Klymak, J., and Coauthors, 2006: An estimate of tidal energy lost to turbulence at the Hawaiian Ridge. J. Phys. Oceanogr., 36, $1148-1164$.

Kunze, E., and J. M. Toole, 1997: Tidally driven vorticity, diurnal shear, and turbulence atop Fieberling Seamount. J. Phys. Oceanogr., 27, 2663-2693.

- E. Firing, J. M. Hummon, T. K. Chereskin, and A. M. Thurnherr, 2006: Global abyssal mixing inferred from lowered ADCP shear and CTD strain profiles. J. Phys. Oceanogr., 36, 1553-1576.

Ledwell, J. R., and A. Bratkovich, 1995: A tracer study of mixing in the Santa Cruz Basin. J. Geophys. Res., 100, 20 681-20 704.

_ A. J. Watson, and C. S. Law, 1998: Mixing of a tracer released in the pycnocline of a subtropical gyre. J. Geophys. Res., 103, 21 499-21 529.

—, E. T. Montgomery, K. L. Polzin, L. C. St. Laurent, R. W. Schmitt, and J. M. Toole, 2000: Evidence for enhanced mixing over rough topography in the abyssal ocean. Nature, 403, 179-182.
Macmillan, S., and S. Maus, 2005: International Geomagnetic Reference Field-The tenth generation. Earth Planets Space, 57, 1135-1140.

McTaggart, K. E., G. C. Johnson, and B. A. Taft, 1996: CTD/O 2 measurements collected on a climate and global change cruise (WOCE Section P18) along $110^{\circ} \mathrm{W}$ during January-April 1994. NOAA Data Rep. ERL PMEL-59, 519 pp.

Munk, W. H., 1966: Abyssal recipes. Deep-Sea Res., 13, 207-230.

—, 1981: Internal waves and small-scale processes. Evolution of Physical Oceanography, B. A. Warren and C. Wunsch, Eds., MIT Press, 264-291.

— and wind mixing. Deep-Sea Res. I, 45, 1977-2010.

Naveira Garabato, A. C., K. L. Polzin, B. A. King, K. J. Heywood, and M. Visbeck, 2004: Widespread intense turbulent mixing in the Southern Ocean. Science, 303, 210-213.

Oakey, N. S., 1982: Determination of the rate of dissipation of turbulent energy from simultaneous temperature and velocity shear microstructure measurements. J. Phys. Oceanogr., 12, 256-271.

Osborn, T. R., 1980: Estimates of the local rate of vertical diffusion from dissipation measurements. J. Phys. Oceanogr., 10, 83-89.

Polzin, K. L., J. M. Toole, and R. W. Schmitt, 1995: Finescale parameterizations of turbulent dissipation. J. Phys. Oceanogr., 25, 306-328.

,,-- J. R. Ledwell, and R. W. Schmitt, 1997: Spatial variability of turbulent mixing in the abyssal ocean. Science, 276, 93-96.

Sanford, T. B., J. H. Dunlap, J. A. Carlson, D. C. Webb, and J. B. Girton, 2005: Autonomous velocity and density profiler: EM-APEX. Proc. IEEE/OES Eighth Working Conf. on Current Measurement Technology, University of Southampton, United Kingdom, IEEE, 152-156.

_ J. F. Price, J. B. Girton, and D. C. Webb, 2007: Highly resolved observations and simulations of the ocean response to a hurricane. Geophys. Res. Lett., 34, L13604, doi:10.1029/2007GL029679.

Schmitt, R. W., J. M. Toole, R. L. Koehler, E. C. Mellinger, and K. W. Doherty, 1988: The development of a fine- and microstructure profiler. J. Atmos. Oceanic Technol., 5, 484-500.

St. Laurent, L. C., and R. W. Schmitt, 1999: The contribution of salt fingers to vertical mixing in the North Atlantic Tracer Release Experiment. J. Phys. Oceanogr., 29, 1404-1424.

— mocline water on the crest of the Mid-Atlantic Ridge. Nature, 448, 680-683.

Stommel, H., and A. B. Arons, 1960: On the abyssal circulation of the World Ocean-I: Stationary planetary flow patterns on a sphere. Deep-Sea Res., 6, 140-154.

Talley, L. D., 2007: Pacific Ocean. Vol. 2, Hydrographic Atlas of the World Ocean Circulation Experiment (WOCE), International WOCE Project Office, 329 pp.

Toggweiler, J. R., and B. Samuels, 1998: On the ocean's large-scale circulation near the limit of no vertical mixing. J. Phys. Oceanogr., 28, 1832-1852.

Toole, J., R. Schmitt, and K. Polzin, 1994: Estimates of diapycnal mixing in the abyssal ocean. Science, 264, 1120-1123.

Waterman, S. N., A. C. Naveira Garabato, and K. L. Polzin, 2010: The Southern Ocean Fine Structure Project: Turbulent dissipation rates and mechanisms in a mixing hotspot. Eos, Trans. Amer. Geophys. Union, 91 (Ocean Science Meeting Suppl.), Abstract PO35K-11.

Webb, D. J., and N. Suginohara, 2001: Vertical mixing in the ocean. Nature, 49, 37-38.

Wyrtki, K., 1961: The thermohaline circulation in relation to the general circulation in the oceans. Deep-Sea Res., 8, 39-64. 